\title{
Erratum: High-resolution computational models of genome binding events
}

Yuan Qi, Alex Rolfe, Kenzie D MacIsaac, Georg K Gerber, Dmitry Pokholok, Julia Zeitlinger, Timothy Danford, Robin D Dowell, Ernest Fraenkel, Tommi S Jaakkola, Richard A Young \& David K Gifford

Nat. Biotechnol. 24, 963-970 (2006); published online 9 August 2006; corrected after print 10 October 2006

In the version of this article initially published, errors appeared in equations 1-6 and in the expression at the end of the first line after equation 4. Some errors appeared in the print only and others in the online pdf only. The correct equations appear below and have been corrected in the HTML and PDF versions of the article.

$$
\begin{aligned}
& f(d)=\sum_{l=d}^{D} l \sum_{a=d}^{l} p_{a}(a) p_{a}(l-a) \\
& p\left(b_{j} \mid \mathbf{y}\right)=\frac{p\left(b_{j}, \mathbf{y}\right)}{p(\mathbf{y})}=\frac{\sum_{\mathbf{b}_{\mathbf{v}}} \iint_{p\left(b_{j}, \mathbf{b}_{\backslash j}, \mathbf{s}, \pi, \mathbf{y}\right) \mathrm{d} s \mathrm{~d} \pi}}{\sum_{\mathbf{b}} \iint_{p}(\mathbf{b}, \mathbf{s}, \pi, \mathbf{y}) \mathrm{d} \mathbf{s} \mathrm{d} \pi} \\
& \text { where } \Sigma_{\mathrm{b}_{\mathrm{j}}} \text { means summing or marginalizing over the values of }\left\{b_{k}\right\}_{\mathrm{k} \neq \mathrm{j}} \text {. } \\
& y_{i}=\sum_{j: f(|i-j|)>0} f(|i-j|) s_{j} b_{j}+n_{i} \\
& \log p(D, \mathbf{Z} \mid \theta, \gamma)=\sum_{i=1}^{N} \sum_{j=1}^{M}\left[Z_{i, j}\left(\log p\left(D \mid Z_{i, j}=1, \theta\right)+\log \gamma_{i, j}\right)\right] \\
& +\sum_{i=1}^{N}\left[\left(1-\sum_{j=1}^{M} Z_{i, j}\right)\left(\log p\left(D \mid \sum_{j=1}^{M} Z_{i, j}=0, \theta\right)+\log \left(1-\sum_{j=1}^{M} \gamma_{i, j}\right)\right)\right] \\
& D=\frac{\sum_{i=1}^{N} \sqrt{\sum_{j=1}^{4}\left(M_{i, j}-T_{i, j}\right)^{2}}}{N}
\end{aligned}
$$

\section{Corrigendum: Tumor antigen-specific induction of transcriptionally targeted retroviral vectors from chimeric immune receptor-modified T cells}

\author{
John Chester, Anja Ruchatz, Michael Gough, Marka Crittenden, Heung Chong, François Loïc-Cosset, Rosa Maria Diaz, Kevin Harrington, \\ Luis Alvarez-Vallina \& Richard Vile \\ Nat. Biotechnol. 20, 256-263 (2002); corrected after print 10 October 2006 \\ In the version of this article initially published, the name of the sixth author was misspelled. The correct spelling is François-Loïc Cosset. The error \\ has been corrected in the HTML and PDF versions of the article.
}

\section{Corrigendum: Integrative model of the response of yeast to osmotic shock}

Edda Klipp, Bodil Nordlander, Roland Krüger, Peter Gennemark \& Stefan Hohmann

Nat. Biotechnol. 23, 975-982 (2005); published online 17 July 2005; corrected after print 10 October 2006

In the version of this article initially published, ' $n$ ' was incorrectly defined on p. 981, the first line after equation 3 , as the "apparent number of osmotically active moles per cell." The correct phrase is, "apparent moles of osmotically active particles per cell." The error has been corrected in the PDF version of the article. 